\title{
Open ITEM Systems are Good ITEM Systems
}

\author{
A. Tatnall ${ }^{1}$ and B. Davey ${ }^{2}$ \\ ${ }^{2}$ School of Information Systems, Victoria University of Technology, Australia \\ ${ }^{2}$ School of Information Technology, RMIT University, Australia
}

Key words: Educational Management, Infrastructure, Information Systems, Information Retrieval, Open Systems, Information Technology.

Abstract: $\quad$ Many educational authorities and third-party developers have, in the past, built ITEM (Information Technology and Educational Management) systems mainly for the benefit of central education authorities rather than schools. In somecases these systems have been designed without thorough consultation with schools. The result has been that many schools have not been able to get as much out of them as might otherwise have been possible.

Experience in designing the hardware and software components of business information systems has shown that open systems, in conjunction with formal software standards, are required toproducesystems thatcanmeet their full potential. It has also been shown that end-users will make much better use of systems that they have had a part in specifying. An inflexible system imposed from above is much less likely to be used effectively than one that clients are able to modify to suit their own requirements.

In this paper we advocate that future ITEM systems should be built as 'open systems' that can be adapted and modified by their users. In this we are arguing for much more than users just being able to select one of several predesigned reports. What we are arguing for is systems that can be added to by the user, and that can be adapted to suit the users' own requirements.

\section{INTRODUCTION}

As the university travel department is running behind schedule, you have to pick up the airline tickets for your forthcoming conference trip yourself. You have driven into the city and parked next to a fire hydrant outside the travel agent's premises. When you come out after collecting your tickets you notea 
young woman smartly dressed in a City Council uniform standing next to your car, typing some data into a hand-held device with a short aerial. The device then prints out the parking ticket which she sticks onto your windscreen. It will do you no good trying to catch up with her to protest that you were in a hurry and were only parked there for a minute or two anyway, as your packing infringement has already been radioed through to the City Council's computer system.

A technician from Telstra ${ }^{1}$ has just spent twenty minutes connecting your new computer network to a Telstra cable for fast Internet access. Before leaving, he types some numbers into a special device connected to his mobile phone. He then gets into his van and plugs this device and the mobile phone into its cradle before driving to his next assignment. When he starts the engine of the van the mobile phone automatically connects to Telstra's head office and up-loads details of the work he has just done at your site. The device also receives details of new jobs to be done later in the afternoon, and commences downloading another part of the new operating system to be installed in the van's computer next week.

The question we will address in this paper is why don't schools make use of technology like this for tasks like checking student attendance, operating library borrowing systems, running school sports meetings and entering student results? The answer is that to some extent, they do. It is possible to purchase systems using technology like PDA (Personal Digital Assistant) terminals and student swipe-cards for this purpose, but what tends to be missing from these systems is the link to the central database in the school administrative system. Our research has shown that although quite a number of Australian schools do use technology like this, they normally have to use it as a separate system unconnected with the school's main administrative system. These special systems operate separately largely due to the inflexibility of central ITEM systems, and the difficulty of using data from one system in the other, with the result that the same data is stored in multiple locations in each school.

\section{SYSTEMS FOR RECORDING STUDENT ABSENCES}

After encountering serious problems with student absences fromclass during the middle of the school day, Flower Meadows High School ${ }^{2}$ implemented a new swipe-card system for recording student attendance. In this system students are issued with their own plastic ID card. Each card has the

${ }^{1}$ An Australian telephone company.

${ }^{2}$ A fictitious name for areal Australian school. 
student's name, date of birth and photograph imprinted on the front, and a magnetic data stripe on the back. Each classroom has a card-reader at the door, and students swipe their ID card through this at the beginning of each class during the day. As the card-readers are networked back to the school administrative office, it is not difficult to see how the system could be used to record student attendance. Special software could then compare data from cards swiped though a card-reader each period with a central student database and print an exception report of student absences. The system could easily be programmed to flag special occurrences, such as when a student who is present in first period and absent in second and third periods is present again in period four. The system would then bring this information to the attention ofrelevant school staff.

Such a system is not new or particularly novel, and schools in several different countries successfully make use of technology like this (Selwood, 1996). In the case we are describing, however, there is a major difficulty, and when looked into further this becomes apparent. FlowerMeadows needs to use the attendance system for initial entry of student enrolments as it must have new ID cards printed as early as possible. When enrolments have stabilised, the school then prints out class lists from the enrolment system and one of the office staff then types these into the main administrative system which is unable to accept external input other than via the keyboard.

Weir High School ${ }^{3}$ issued all their teaching staff with a PDA (Palm Pilot III) at the start of the school year. Each PDA is loaded with special software and copies of student class lists for every class in the school, along with a copy of the school timetable. At the beginning of each period, teachers enter student absences (or lateness) into the device; it is presumed that all students not so marked are present. If a teacher is away then the replacement teacher who gets the 'extra' simply uses their own PDA which, like all the others, has been loaded with all the class lists. At the end of the day, or when a teacher has no more classes, they upload the absences into one of the PC data entry stations in each staffroom. As these PCs have been fitted with a special cradle to accommodate a PDA for data transfer, this is quite a simple task that normally takes only about 10 seconds.

During upload the system also checks to see when this PDA last had an update of its class lists, and whether there have been any changes since that time. If there have been changes a message appears on the PC screen asking the teacher to be patient and wait until new class lists have been downloaded to their device (Harper, 2000). After all teachers have uploaded their data, the central system is able to print out a series of reports, and lists of absences each period of the day. 
Although this is still a developing technology, some schools are also making use of this system on the portable PDAs on school excursions to ensure that no student gets left behind when the bus leaves. Others are entering disciplinary data such as when a student has been caught smoking, or fighting. Like the swipe-card system, however, the problem is that this system operates entirely separately from the school's central administrative system.

\section{PROBLEMS WITH NON-INTEGRATED FUNCTIONAL SYSTEMS}

Not only is the re-entry of data, required when using either of these systems, a waste of time and resources, but it also violates one of the main principles of database management (Date, 1983): that data should be stored in one place, and one place only. (It should be noted that there should always be a back-up copy of any database. What we are pointing out here is that there should only be one copy of the database in use.)

At this point a comparison with business information systems is useful. Traditionally, businesses have often been organised along functional lines. From early times, information systems were designed to support business functions such as accounting, manufacturing, finance, human resources, marketing and so on. In the early function-specific information systems, data was typically stored in file format, with data of a given type being stored in a particular file independently of all other data (Tatnall et al., 2000). While these systems had their benefits, they also had problems (Reyes, 1998). For instance, data collected for use by one function-specific information system would typically not be available to another. This made systems of this type potentially quite inefficient. Specific information systems can, however, be designed to act together to produce an integrated information system whose purpose is to provide for the flow of information across all levels and functions of the organisation (Tatnall et al., 2000). Data is stored once only, without duplication, and is able to support all activities relevant to the organisation, so improving communication between parts, or functions, of the organisation.

Using function-specific systems that are not integrated with the central database means that there will need to be multiple copies of the student database (for example), each of which must be frequently updated (Tatnall et al., 2000). The difficulty is that when there are two or more different, unrelated student databases, any changes, such as new enrolments, changed student details and so on that occur, must be made to each database every time they occur. Human weakness means that with almost complete 
certainty, there will be a time when this does not occur and only one of the databases is updated. This means that the other database then becomes inaccurate.

The reason that Flower Meadows and Weir High Schools are unable to transfer the data from one system to the other is that the school administrative system that they both use has been designed as a functionspecific system. It has been designed not to allow the importation of data from other systems, and not to allow other systems to directly access its own database. Presumably the designers of the school administrative system, provided by the Ministry of Education, had concerns about data security and integrity and so designed it that way. This system allows download of data, but nothing more.

\section{WHO 'OWNS' THE ITEM SYSTEM?}

In several Australian states, schools' administrative computing systems were built by central educational authorities and issued free (or at low cost) to schools. The primary motivation for doing this was to provide a reporting mechanism from schools back to the centre. Schools' administrative computing needs were not the main consideration (Tatnall, 1995). The general distribution of these systems to schools meant that schools could then be instructed that they must use them to provide the required reports back to the central authority.

While understanding why this approach was adopted, and not wanting to denigrate the needs of central educational authorities for information, we would argue that in future it would be much better if individual schools, rather than school systems, were seen as the prime clients by systems developers.

At issue here is who should be seen as the client. Who should the systems developers speak with about the systems requirements? There is a great deal of information systems literature that points to the necessity of involving users in the process of designing information systems (Fuller \& William, 1994; Lindgaard, 1994; Alter, 1996; Lawrence et al., 1997) if we want those systems to be used to their full potential. Lawrence et al. (1997) stress the need to consult with users, and Lindgaard (1994) notes that a large body of research has shown that potential users do not make best use of information systems unless they feel that these systems have been designed with their involvement and in their interest. Fuller and William (1994) point out that when business users think that central computing departments have been unresponsive to their needs they often take application development into their own hands, do their own thing, and ignore the central authority. If the 
central education authority is seen as the client then it is unlikely that schools will be entirely happy with the end product. It is more likely that they will do as Fuller and William suggest and bypass the central system.

There are many examples in business of information systems being designed for both central and local use. These systems can be built to offer the best of both worlds: a secure centralised database, combined with a degree of local autonomy in use. The technology and tools exist so that such systems need not compromise data security when offering local users some flexibility in how they use the data, and what other systems they allow to be connected. The theoretical advantages of such integrated systems (Tatnall \& Davey, 1995) has been understood by those building business information systems for many years. The problem, rather, is one of system developers looking only to the central authority and not acknowledging that schools have differing information needs.

\section{ISSUES OF DATA REDUNDANCY, CLOSED SYSTEMS AND INTEGRATION}

At a first level of abstraction it is convenient to compare function-specific systems with integrated systems, but we will now look at what this means in practical terms. The main difference between having a number of unrelated functional systems and an integrated system is that in the first case, each system has its own database which is not shared with any other system, meaning that there is a great deal of data redundancy. The main issue then becomes: is the data stored in such a way that it can be accessed by the other systems? This does not necessarily imply physically storing all data in a single central database, but more likely would result in data stored in several locations that are conceptually linked together into a single database. If a system is set up this way it is comparatively easy to link in other functional systems at a later date.

To get an idea of the magnitude of the problem, imagine that a particular school has function-specific library borrowing, student attendance, student results and sports meeting systems as well as its central administrative system. As each of these systems involves lists of students there will need to be five separate, unrelated copies of the student database maintained and used in the school. When a student transfers into or out of the school, five different databases need to be updated. This can be done by just updating the central system then downloading this data again to each of the other systems but, however it is done, it is a substantial and time wasting task that has lots of potential for going wrong, with the result that one or more of the databases becomes corrupted or not updated properly. Carefully choice of 
additional functional systems that are able to co-operate and share data can reduce this difficulty (Athey et al., 1991; Selwood, 1996), but the problem of an inflexible central system still remains.

When the initial system is built as a closed system that allows no other systems access to its data, except perhaps by download, data integration and the use of a single common database is not possible. In the cases we have highlighted, both the system using PDAs and that using the swipe-cards are function-specific. Both were purchased from third-party commercial suppliers who were unable to integrate their systems with the ITEM system provided by the central education authority as this was designed as a closed system. The result is data duplication and waste.

\section{PREDICTING EACH SCHOOL'S FUTURE INFORMATION NEEDS}

Many of the ITEM systems used in managing schools around the world are good, well designed systems. Unfortunately, however, some were designed primarily to satisfy the information needs of central education authorities (Tatnall, 1995) and others appear to have been designed on the premise that the designers knew all about schools' information needs and so need not offer any third-party expansion options. What is more, the use of such a closed, proprietary-like approach means that they are also premised on the assumption that the designers alone will be able to modify them to satisfy future needs. It assumes that the designers know what schools will need in the future, and that they will be able to incorporate these changes into their systems. On this premise they construct closed systems that schools cannot add to or change. This creates a problem that Frank and Fulmer (1998:94) put this way: "...it is a common experience that the information systems developer who limits development to working with what is instead of what should be has created a static system that is outdated and serves only to audit a system going nowhere."

Because schools are different, their information needs are also different. Flower Meadows and Weir High Schools each saw the need to develop attendance systems, and each came up with a different solution. As the designers of the central ITEM system did not foresee any need for schools to use solutions for student attendance other than the one they had provided, they did not offer the facility for other systems to connect to theirs. They did allow data download, but nothing more. In similar vein there are many other situations in which a systems designer could not possibly come up with a perfect solution that would be suitable for all schools into the future. Perhaps the ITEM system provided to a school does not link in with the library 
borrowing system, perhaps it does not handle school sports and the school wants to add this feature, perhaps it handles lateness in a way that is not appropriate for this particular school, perhaps it needs to do something else that no one has thought of yet. In these events, we would argue that the ITEM software should empower (Davey \& Reyes, 1998) an individual school by enabling it to make appropriate changes in the way the software operates, or to add new systems to work with, and be integrated with, the one provided.

We acknowledge that not all schools will be able, or even want, to modify these systems, but argue that this facility should be available to them. This is often not the case at present.

\section{ALTERNATIVE APPROACHES AND RECOMMENDATIONS}

We have argued that ITEM systems must be open systems that allow the easy integration of new third party products where appropriate. Within this constraint, many different open architectures are possible, but some form of client-server or distributed database (Davey \& Tatnall, 1997; Davey \& Reyes, 1998) offering read-only access to some tables of the central database would probably be best (Tatnall \& Tatnall, 1998). The important point is that only one copy of data, such as lists of students and teaching staff, should be kept. The system should be open to accredited, conforming applications to have read/write access to this data, while other (non-conforming) applications should be granted read-only access. Such a system could look something like the diagram in Figure 1 below.

As well as the central database, use could be made of a data warehouse that could be set up to allow any users (accredited or not) easy and rapid access to specialised queries on selected data.

For any access like this to be possible, however, the data should be stored in a commonly accessible format. An ODBC format useable by database systems like Microsoft Access, and programming languages like Visual Basic is preferable as it means that users and third-party developers can easily access this data via other custom-designed programs. The data structure must be clearly set out and documented, with information and help for potential school developers. Documentation on the operation and design of the system should be clear, and should be written at a number of different levels suitable for users, school-level developers, and third-party developers. 


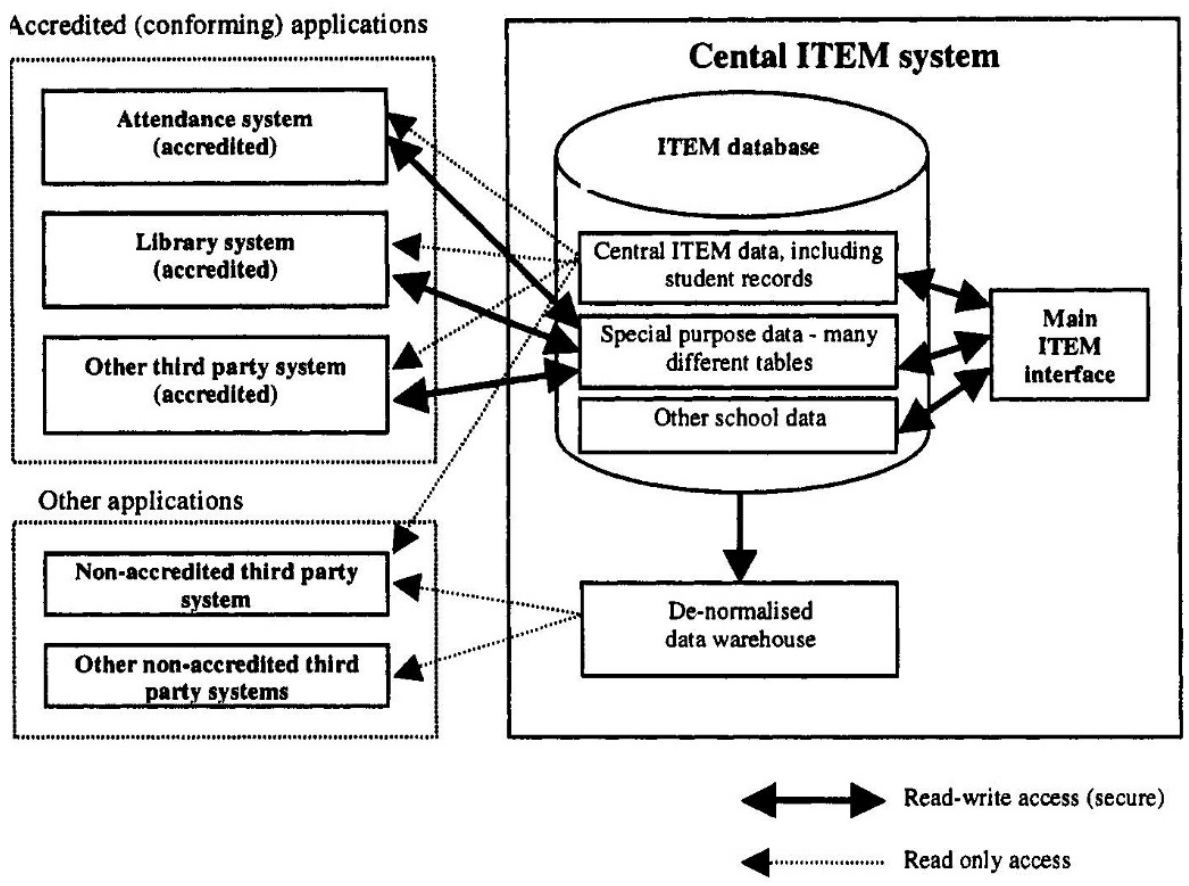

Figure 1: An architecture for an open ITEM system

\section{CONCLUSION}

Generally speaking, the current generation of ITEM systems are well designed functional systems that provide useful reports, and the standard operations that the designers thought that schools might require. New systems will, however, need to do more. Future systems will need to offer facilities and perform tasks that neither schools nor developers have thought of yet. To do this these new systems must be open and flexible so that they can be easily extended. They must also be able to interface easily with other third-party systems not yet designed. Systems designers can't predict the future, but they can allow for it by making their systems open.

We argue that if future ITEM systems are open systems that incorporate features of this sort they will be a lot more useful to their ultimate clients schools. 


\section{REFERENCES}

Alter, S. (1996). Information systems: A managementperspective(2nd ed.). Menlo Park, CA: Benjamin Cummins.

Athey, T.H., Day, J.C., \& Zmud, R.W. (1991). Computers and end-user software. New York: Harper Collins.

Date, C.J. (1983). Database: A primer. USA: Addison Wesley.

Davey, B., \& Tatnall, A. (1997). Distributed ITEM for the future: Moving towards client-server systems. In A.C.W. Fung, A.J. Visscher, B.Z. Barta, \& D.C.B. Teather (Eds.), Information technology in educational management for the schools of the future. London: Chapman \& Hall.

Davey, B., \& Reyes, G. (1998). Overcoming resistance to integration: using client-server systems and data warehousing. In C.L. Fulmer, B.Z. Barta, \& P. Nolan (Eds.), The integration of information for educational management. Whitefield, Maine: Felicity Press.

Frank, F.P., \& Fulmer, C.L. (1998). The dysfunctional side of educational organizations: Themes from clinical information systems development. In C.L. Fulmer, B.Z. Barta, \& P. Nolan (Eds.), The integration of information for educational management. Whitefield, Maine: Felicity Press.

Fuller, F., \& William, M. (1994). Computers and information processing. Massachusetts: Boyd \& Fraser.

Harper, R. (2000). A breakthrough in attendance monitoring and reporting. Australia: RollCall. [http://www.rollcall.Australia.au]

Lawrence, D.R., Shah, H.U., \& Golder, P.A. (1997). Business users and the information systems development process. In B.Z. Barta, A. Tatnall, \& P. Juliff (Eds.), The place of information technology in management and business education. London: Chapman \& Hall.

Lindgaard, G. (1994). Usability testing and system evaluation. London: Chapman \& Hall.

Reyes, M.G. (1998). A model illustrating the implication of information integration on educational administration. In C.L. Fulmer, B.Z. Barta, \& P. Nolan (Eds.), The integration of information for educational management. Whitefield, Maine: Felicity Press.

Selwood, I.D. (1996). Information technology to record and monitor school attendance. In A.C.W. Fung, A.J. Visscher, B.Z. Barta, \& D.C.B. Teather (Eds.), Information technology in educational management for the schools of the future. London: Chapman \& Hall.

Tatnall, A. (1995). Information technology and the management of Victorian schools: Providing flexibility or enabling better central control? In B.Z. Barta, M. Telem, \& Y. Gev (Eds.), Information technology in educational management. London, Chapman \& Hall. 
Tatnall, A., \& Davey, B. (1995). Executive information systems in school management: A research perspective. In J.D. Tinsley, \& T.J. van Weert (Eds.), World Conference on Computers in Education VI. WCCE'95. Liberating the learner. London: Chapman \& Hall.

Tatnall, A., Davey, B., Burgess, S., et al. (2000). Management information systems: Concepts, issues, tools and applications (2nd ed.). Melbourne: Data Publishing.

Tatnall, A., \& Tatnall, B. (1998). Data integration in a training institute: Modelling a client-server solution. In C.L. Fulmer, B.Z. Barta, \& P. Nolan (Eds.), The integration of information for educational management. Whitefield, Maine: Felicity Press. 